\title{
A physiological classification of viridans streptococci by use of the API-20STREP system
}

\author{
G. L. FRENCH*, H. TALSANIA, J. R. H. CHARLTON† and I. PHILLIPS
}

Departments of Microbiology and †Community Medicine, United Medical and Dental Schools of Guy's and St Thomas's, St Thomas's Campus, London SE1 7EH

\begin{abstract}
Summary. Physiological reactions of viridans streptococci were examined by the API20STREP system and a selection of conventional tests. Cluster analysis of these results produced a classification similar to a taxonomic scheme based on that of Colman and Williams. The organisms could be divided into the six recognised species-Streptococcus mutans, S. bovis, S. mitior, S. sanguis, S. salivarius and $S$. milleri. Analysis confirmed that $S$. mitior and $S$. sanguis can be distinguished in the API20STREP test by hydrolysis of arginine but not by dextran production. Although $S$. mutans, $S$. mitior and $S$. sanguis can be divided into two further subgroups, the taxonomic significance of this is unclear. With this means of classification, most organisms could be identified easily by a small number of tests. API-20STREP is convenient for performing physiological tests on viridans streptococci, but the information provided by the manufacturers in regard to identification and nomenclature is in need of revision.
\end{abstract}

\section{Introduction}

Viridans streptococci comprise a proportion of the normal mouth and bowel flora, have a relatively low virulence for man, and show variable reactions with Lancefield's antisera (Sherman, 1937; Colman, 1976; Hardie and Bowden, 1976; Parker and Ball, 1976; Facklam, 1977). Although they are named "viridans", not all produce $\alpha$-haemolysis; this property of "greening" on blood agar has been recognised for many years to be affected by the growth medium used (Medical Research Council, 1929). The viridans streptococci of the mouth are associated with caries, dental sepsis, endocarditis, septicaemia and abscess formation.

Because the viridans streptococci give poor and variable reactions in serological and conventional physiological tests and, in many cases, are of relatively low virulence, they have been studied less extensively than the $\beta$-haemolytic streptococci. Consequently there is no universally accepted system for the study of the taxonomy of viridans streptococci and in most studies some strains remain unclassified no matter which identification scheme is adopted (Drucker and Melville, 1971; Colman and Williams, 1972; Parker and Ball, 1976;

Received 4 June 1988; revised version accepted 29 Sep. 1988.

* Present address for correspondence: Professor G. L. French, Department of Microbiology, The Chinese University of Hong Kong, Shatin, N.T., Hong Kong.
Hardie and Marsh, 1978). Furthermore, there is disagreement over grouping and nomenclature among different authorities. Facklam (1977) in the USA recognised the following: Streptococcus salivarius, $S$. mutans, $S$. sanguis types I and II, $S$. mitis, $S$. MG-intermedius, $S$. anginosus-constellatus, $S$. bovis, and three species that are only rarely found in man-S. acidominus, $S$. morbillorum and $S$. uberis. This scheme is used in the Streptococcal Reference Laboratory at the Centers for Disease Control, Atlanta. However, Colman and Williams (1972) in the UK did not accept $S$. sanguis II or $S$. mitis as described by Facklam, but placed organisms resembling these species in a group called $S$. mitior, defined on the basis of cell-wall carbohydrate composition. They identified dextran-producing and non-producing strains of both $S$. sanguis and $S$. mitior, considering these variants taxonomically significant. Colman and Williams classified strains resembling Facklam's $S$. $M G$-intermedius and $S$. anginosus-constellatus as $S$. milleri, and with Parker and Ball (1976) did not consider that there was sufficient evidence for subdivision of this group. Coykendall et al. (1987) concluded from DNA homology studies that $S$. milleri, $S$. constellatus and $S$. intermedius should be described as a single species, $S$. anginosus. Colman and Williams divided $S$. bovis into two groups corresponding to Facklam's "typical" and "variant" strains (Facklam, 1972, 1977). This scheme is used in the Streptococcal 
Reference Laboratory at the Central Public Health Laboratory, Colindale, London, and has been generally adopted in Bergey's Manual of Systematic Bacteriology (Hardie, 1986). The differences between the British and American classification schemes were discussed by Facklam (1984).

Undoubtedly some of the disagreement about taxonomy is related to the variation in the results of tests used for the identification of viridans streptococci. Results of tolerance tests, such as growth in salt, bile and at different temperatures, vary significantly amongst different studies, and results of tests for the production of dextran and levan again depend on the system used.

The API-20STREP system is a commercial test kit for the identification of streptococci; it utilises many of the conventional streptococcal tests in addition to others that include the production of a diverse range of enzymes. The system identifies viridans streptococci on the basis of the Facklam classification, but includes additional biotypes for several species. With the API system, $S$. pneumoniae can be confused with $S$. sanguis unless further tests such as bile solubility or optochin sensitivity are performed. The API-20STREP kit was reviewed favourably by Colman and Ball (1984) for the identification of viridans streptococci, but this system is not the same as the API-20S system described by Nachamkin et al . (1982) and Appelbaum et al. (1984). The API-20STREP system gave consistent results for the hydrolysis of arginine and aesculin (Price et al., 1986).

To clarify the taxonomy of the viridans streptococci we performed a physiological classification of a collection of these organisms using the API20STREP system and several other potentially reproducible and discriminatory tests. The API20STREP system was assessed for its reproducibility and not used for identification of strains. The data were analysed by cluster analysis.

\section{Materials and methods}

\section{Organisms}

Clinical isolates from St Thomas's Hospital, London, or clinical and reference strains kindly donated by colleagues were examined. Most of the 178 strains were isolated from the mouth (63) or blood (68); 51 isolates were from cases of endocarditis and eight were from animals. There were 12 duplicate strains, usually identical strains held in different culture collections under different codes or strains with the same code number donated from different institutions.

\section{Serological reactions}

The Streptex method was used to test for streptococci of Lancefield's groups A, B, C, D, F and G. Group D streptococci react poorly in this test, but nearly always give positive results in the bile-aesculin test. Some strains of $S$. mutans had been serotyped by the donors (table III).

\section{Conventional characterisation tests}

These were based on the methods of Cowan (1974) and those recommended by the Streptococcal Reference Laboratory (Waitkins et al., 1980). Tests for catalase production and urease activity followed Cowan's method 1 , and arginine and aesculin hydrolysis were assessed by a combination of Cowan's agar methods. Fermentation of ribose, L-arabinose, mannitol, sorbitol, lactose, trehalose, inulin and raffinose was determined by culture in serum water sugars (Cowan, 1974). Starch hydrolysis was tested by the method of Waitkins et al. (1980). To detect the production of $\mathrm{H}_{2} \mathrm{O}_{2}$, organisms were incubated for $24 \mathrm{~h}$ in Todd Hewitt broth (Southern Group Laboratories, no. $0510 \mathrm{H}$ ), the culture was centrifuged at $3000 \mathrm{rpm}$ for $10 \mathrm{~min}$, and the supernate decanted; a Merckoquant Peroxide Test strip (Merck, Darmstadt, FDR) was dipped into the deposit and, after $5 \mathrm{~s}$, the colour reaction was compared with the manufacturer's colour chart. For the production of dextran and levan, cultures in glucose and sucrose broths (Bailey and Oxford, 1958, 1959) were incubated for 5 days and then centrifuged at $3000 \mathrm{rpm}$ for $10 \mathrm{~min} ; 0.5 \mathrm{ml}$ of the glucose supernate was placed in one universal container and $0.5 \mathrm{ml}$ of sucrose supernate in each of two others, and $4.5 \mathrm{ml}$ of $10 \%$ sodium acetate was added to all three containers; 2.5 volumes of absolute alcohol was added to the one containing glucose (control) and to one of the sucrose samples, and 1.2 volumes to the other. All the universal containers were mixed well and incubated at room temperature. The formation of precipitates in the sucrose solutions within $3 \mathrm{~h}$ indicated the production of polysaccharides; the glucose solution (control) remained clear. A precipitate in both sucrose bottles indicated dextran production; precipitation in only the one containing 2.5 volumes of alcohol indicated levan production.

\section{The API-20STREP system}

This commercial kit tests for the following characters: possession of seven enzymes (pyrrolidonylarylamidase, $\alpha$-galactosidase, $\beta$-galactosidase, $\beta$-glucuronidase, alkaline phosphatase, leucine aminopeptidase and arginine dihydrolase), production of acetoin (the Voges-Proskauer, VP, test), hydrolysis of hippurate and aesculin, and fermentation of ribose, L-arabinose, mannitol, sorbitol, lactose, trehalose, inulin, raffinose, starch and glycogen. The test for the possession of arginine dihydrolase was regarded as equivalent to a test for arginine hydrolysis. Organisms were grown for $24 \mathrm{~h}$ on blood agar in $\mathrm{CO}_{2} 10 \%$ in air. The inoculum was a heavy suspension in distilled water, to a turbidity between MacFarland 
Tubes 5 and 6, and the galleries were inoculated according to the manufacturer's instructions. After incubation for $4 \mathrm{~h}$ at $37^{\circ} \mathrm{C}$ in air, the reagents were added and colour changes were read by comparison with the API chart in daylight. The reactions for aesculin and arginine hydrolysis, and all the fermentation tests were read after $24 \mathrm{~h}$, as recommended.

\section{Cluster analysis}

This was performed with the Clustan suite of programs (Clustan 1c, May 1975) (Wishart, 1975) running on mainframe computers at the University of London's computer centre. Analyses were performed with the Simple Matching Coefficient (Clustan coefficient 4) (Sokal and Sneath, 1973), and the squared Euclidean distance (Clustan coefficient 2) (Sokal and Sneath, 1973). The similarity matrices were then analysed by three clustering methods: single linkage (Nearest neighbour) (Sneath, 1957), Gower's Median (Gower, 1967) and Ward's Error Sum of Squares (Ward, 1963). After initial clustering had been obtained with each of these methods the classification was tested within Clustan by a relocation technique (Wishart, 1975).

\section{Results}

\section{Comparison between conventional and API-}

\section{STREP test results}

Identical results were obtained in conventional and API-20STREP tests for the fermentation of ribose, arabinose, mannitol, sorbitol and trehalose. However, there were some discrepancies between the two methods in tests for hydrolysis of arginine and aesculin, production of acetoin, and fermentation of raffinose, inulin and lactose (table I). Except for inulin fermentation the API system gave a

Table I. Comparison between physiological test results produced by API-20STREP (API) and conventional (Con) methods

\begin{tabular}{lcc}
\hline \multicolumn{1}{c}{ Test } & $\begin{array}{c}\text { API-positive } \\
\text { Con-negative }\end{array}$ & $\begin{array}{c}\text { Con-positive } \\
\text { API-negative }\end{array}$ \\
\hline $\begin{array}{l}\text { Hydrolysis of: } \\
\text { arginine }\end{array}$ & $12(\mathrm{a})$ & 0 \\
$\begin{array}{l}\text { aesculin } \\
\begin{array}{l}\text { Production of: } \\
\text { acetoin (VP) }\end{array}\end{array}$ & $13(\mathrm{~b})$ & 0 \\
$\begin{array}{l}\text { Fermentation of: } \\
\text { raffinose } \\
\text { inulin } \\
\text { lactose }\end{array}$ & $10(\mathrm{c})$ & 0 \\
\hline
\end{tabular}

(a) 12 S. sanguis; (b) $10 \mathrm{~S}$. sanguis, $3 \mathrm{~S}$. milleri; (c) $8 \mathrm{~S}$. salivarius, $2 S$. milleri; (d) $5 S$. salivarius, $1 S$. mitior; (e) $6 S$. mutans, $5 S$. mitior and $8 S$. sanguis; (f) $2 S$. mitior, $1 S$. sanguis. greater number of positive results for the above tests than the conventional methods. We have demonstrated previously that the API-20STREP results for arginine and aesculin hydrolysis are taxonomically more consistent for the speciation of organisms resembling $S$. sanguis and $S$. mitior, (Price et al., 1986) and table I shows that the system is also more satisfactory for testing acetoin production in strains of $S$. salivarius and $S$. milleri; these are typically positive in this test. Differences in carbohydrate fermentation results appeared to be less significant taxonomically. Therefore, the API20STREP results were adopted and are presented in this paper.

\section{Tests uniformly positive or negative}

All 178 viridans streptococci were gram-positive cocci in chains; they did not produce catalase, hydrolyse hippurate or ferment arabinose; they gave negative results in tests for pyrrolidonylarylamidase activity and positive for leucine aminopeptidase. Only one strain (STH28, a probable $S$. bovis II) showed $\beta$-glucuronidase activity. As these tests were not useful for taxonomy of viridans streptococci, they were not used in the analyses.

\section{Classification of viridans streptococci}

Classifications can be constructed intuitively by giving special weight to certain test results that are considered traditionally to have more importance than others. This is in contrast to numerical or Adansonian taxonomy in which all tests are given equal weight and the taxonomic divisions are made mathematically. We analysed the physiological results by both intuitive and numerical methods.

Intuitive classification. We have previously shown that organisms resembling $S$. sanguis that are arginine-negative and aesculin-positive in the API20STREP system also have a low cell-wall rhamnose content, and thus can be classified as $S$. mitior; similar organisms that are arginine-positive and aesculin-negative have high rhamnose contents and are S. sanguis (Price et al., 1986). With this modification of the Colman and Williams classification, the collection of strains could be divided intuitively into six species: $S$. mutans, $S$. salivarius, $S$. milleri, S. sanguis, S. mitior and S. bovis. Dextranpositive and dextran-negative variants of both $S$. sanguis and $S$. mitior were recognised.

Of the 57 strains of $S$. mutans, 26 resembled Perch's biotype 1 (Perch et al., 1974); seven of these were serotype a, seven serotype c, three serotype e, four serotype $f$ and the remainder were not typed. 
Five strains hydrolysed arginine and were classified, therefore, as Perch biotype 2; four of these were serotype $b$, and the other serotype g. Seven argininenegative strains were serotype $d$ or g. None fermented raffinose (unlike all but one of the other $31 \mathrm{~S}$. mutans strains) and were therefore regarded as Perch biotype 3 . In contrast with the expected reactions for biotype 3 , all but one of these strains hydrolysed aesculin, and none produced $\mathrm{H}_{2} \mathrm{O}_{2}$. None possessed $\alpha$-galactosidase, although this enzyme was present in 30 of the $31 S$. mutans strains of other biotypes.

Only three of the 15 strains thought to be $S$. bovis resembled $S$. bovis II; they hydrolysed aesculin but not arginine, and only one hydrolysed starch. All produced acetoin but not dextran, and none fermented mannitol or sorbitol. All three were identified as $S$. bovis II by API-20STREP.

Five organisms could not easily be classified. These were strain STH102, an $\alpha$-haemolytic organism resembling $S$. sanguis but $\mathrm{H}_{2} \mathrm{O}_{2}$-negative; strains STH11 and STH20, two highly unreactive $\alpha$-haemolytic strains; and the reference strains NCTC 7868 and HF/F90A (equivalent to $S$. sanguis ATCC 12369), which are similar to $S$. sanguis but are $\beta$-haemolytic and $\mathrm{H}_{2} \mathrm{O}_{2}$-negative. Table II shows the results for the intuitive classification if the reference strains are classified with $S$. sanguis; the three other unidentified strains and the three $S$. bovis II strains are excluded.

Cluster analysis. All analyses produced identical results with the technique of relocation, and for the

Table II. Intuitive classification of 155 strains of viridans streptococci

\begin{tabular}{|c|c|c|c|c|c|c|c|}
\hline \multirow[b]{2}{*}{ Test } & \multicolumn{7}{|c|}{ Percentage of strains* that gave positive results } \\
\hline & $\begin{array}{c}\text { MUT } \\
(38)\end{array}$ & $\begin{array}{l}\text { SAL } \\
(17)\end{array}$ & $\begin{array}{c}\text { MIL } \\
(25)\end{array}$ & $\begin{array}{c}\text { SAN } \\
(32)\end{array}$ & $\begin{array}{c}\mathrm{MD}+ \\
(12)\end{array}$ & $\begin{array}{c}\text { MD - } \\
(17)\end{array}$ & $\begin{array}{l}\text { BO1 } \\
(14)\end{array}$ \\
\hline \multicolumn{8}{|l|}{ Haemolysis: } \\
\hline$\alpha-$ & 3 & 12 & 52 & 88 & 100 & 100 & 29 \\
\hline$\beta-$ & 0 & 6 & 16 & 6 & 0 & 0 & 0 \\
\hline Non- & 97 & 82 & 32 & 6 & 0 & 0 & 71 \\
\hline \multicolumn{8}{|l|}{ Hydrolysis of: } \\
\hline Arginine & 13 & 0 & 100 & 100 & 0 & 0 & 0 \\
\hline Aesculin & 97 & 100 & 88 & 100 & 33 & 41 & 100 \\
\hline Starch & 0 & 0 & 0 & 12 & 0 & 0 & 100 \\
\hline Urea & 0 & 71 & 0 & 0 & 0 & 0 & 0 \\
\hline \multicolumn{8}{|l|}{ Production of: } \\
\hline Acetoin (VP test) & 100 & 100 & 100 & 0 & 0 & 0 & 100 \\
\hline $\mathrm{H}_{2} \mathrm{O}_{2}$ & 0 & 0 & 16 & 94 & 100 & 100 & 0 \\
\hline Dextran & 97 & 0 & 0 & 84 & 100 & 0 & 44 \\
\hline Levan & 0 & 94 & 0 & 0 & 0 & 0 & 0 \\
\hline \multicolumn{8}{|l|}{ Fermentation of: } \\
\hline Mannitol & 100 & 0 & 8 & 0 & 0 & 0 & 93 \\
\hline Sorbitol & 92 & 0 & 0 & 0 & 8 & 0 & 0 \\
\hline Raffinose & 79 & 94 & 12 & 38 & 92 & 53 & 100 \\
\hline Inulin & 87 & 41 & 0 & 56 & 0 & 0 & 100 \\
\hline Lactose & 97 & 94 & 80 & 94 & 100 & 100 & 100 \\
\hline Trehalose & 95 & 71 & 100 & 97 & 33 & 18 & 93 \\
\hline Ribose & 3 & 0 & 0 & 3 & 0 & 29 & 0 \\
\hline Starch & 0 & 59 & 40 & 44 & 75 & 47 & 100 \\
\hline Glycogen & 0 & 0 & 4 & 0 & 0 & 0 & 100 \\
\hline \multicolumn{8}{|l|}{ Enzyme activity: } \\
\hline$\alpha$-galactosidase & 76 & 12 & 23 & 38 & 92 & 47 & 100 \\
\hline$\beta$-galactosidase & 0 & 94 & 0 & 0 & 0 & 12 & 0 \\
\hline alkaline-phosphatase & 0 & 12 & 100 & 53 & 92 & 47 & 0 \\
\hline
\end{tabular}

$\mathrm{MUT}=S$. mutans $; \mathrm{SAL}=S$. salivarius $; \mathrm{MIL}=S$. milleri $; \mathrm{SAN}=S$. sanguis $; \mathrm{MD}+=S$. mitior, dextran-positive $; \mathrm{MD}-=S$. mitior, dextran-negative; $\mathrm{BO} 1=S$. bovis $\mathrm{I}$.

* These results exclude duplicates, three strains of probable $S$. bovis II, and three unclassifiable organisms, but group the atypical reference strains NCTC 7868 and HF/F90A (ATCC 12369) with S. sanguis. 
single linkage method there was no difference between the clustering produced by the Simple Matching Coefficient (Clustan coefficient 4) and the squared Euclidean distance metric (Clustan coefficient 2). Gower's (Median) clustering method produced large numbers of small clusters, and was unhelpful. The single linkage method with the Simple Matching Coefficient produced a cluster analysis that placed organisms resembling $S$. sanguis, $S$. mitior and $S$. milleri in one large group, and $S$. salivarius, $S$. mutans and $S$. bovis in another. Moreover, with this method many isolates were placed into small, often single-strain clusters, that joined the larger groups independently. In contrast, Ward's method with Clustan coefficient 2 produced clusters that corresponded very closely with intuitive groupings. Therefore, detailed results are presented only for this method of cluster analysis.

Ward's method can be applied to dissimilarity distance (metric) coefficients only, and dissimilarities are expressed in distance units rather than percentages. The pyramidal dendrogram produced by this method is shown in the figure. Two large clusters, containing 64 strains and 114 strains respectively, are separated by a distance of about 15 units. The smaller cluster contains the $S$. mutans (group I) and $S$. bovis (group II) strains, and the larger cluster divides into two subclusters separated by $7 \cdot 3$ units, one containing strains resembling $S$. milleri (group VI) and $S$. salivarius (group V), and the other containing those corresponding to $S$. sanguis (group IV) and $S$. mitior (group III). These general groupings are similar to the intuitive classification based on the physiological reactions.

Group I (table III) contains all 47 strains identified intuitively as $S$. mutans. It divides into two subgroups separated by a distance of about 1.5 units. Subgroup IB (34 strains) contains 28 strains identified intuitively as $S$. mutans biotype 1 (including the reference strains NCTC 10449 and 10923 and their duplicates), and all six biotype- 2 strains. Subgroup IA (13 strains) contains the remainder of the $S$. mutans isolates - all the biotype-3 strains (including the reference strain NCTC 10922) and all four $\alpha$-galactosidase-negative biotype- 1 strains (including the reference strain NCTC 10919). All the strains that make up subgroup IA can be distinguished from those of subgroup IB by their failure to produce $\alpha$-galactosidase.

Group II (17 strains) (table III), contains all isolates identified intuitively as $S$. bovis, with the exception of the atypical $S$. bovis II strain STH28

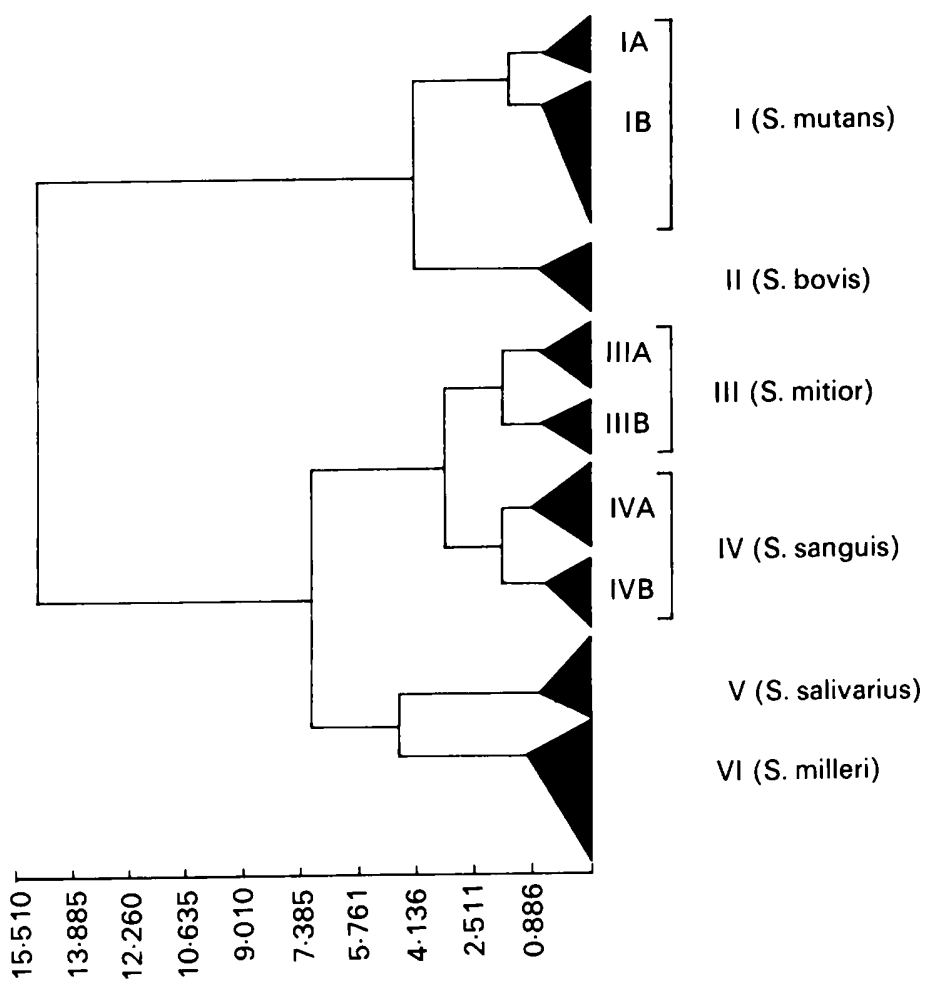

Figure. Cluster analysis of the results of 23 physiological tests for 178 strains of viridans streptococci; the dendrogram was produced by Ward's method with the squared Euclidean distance metric (Clustan coefficient 2). 
Table III. Biochemical and enzymatic reactions of strains in cluster I from conventional and API-20STREP tests

Strain

Reactions

\begin{tabular}{lccccccccc}
\hline $\begin{array}{l}\text { STH } \\
\text { code }\end{array}$ & $\begin{array}{c}\text { Original } \\
\text { code }\end{array}$ & Ser & H & AESU APDL & MSARILT & Hi & RSG & PABBPL & APICODE
\end{tabular}

Group IA (S. mutans)

$\begin{array}{llll}151 & \text { OIHI } & \text { d } & \text { G } \\ 159 & \text { OMZ/65 } & \text { g } & \text { G } \\ 142 & \text { TH62 } & \text { g } & \text { G } \\ 118 & \text { TH62 } & \text { g } & \text { G } \\ 133 & \text { K1 } & \text { g } & \text { G } \\ 145 & \text { P4 } & \text { e } & \text { G } \\ 125 & \text { KPSK 2 } & \text { c } & \text { G } \\ 152 & \text { NCTC 10922 } & \text { d } & \text { G } \\ 149 & \text { NCTC 10919 } & \text { a } & \text { G } \\ 117 & 279 & \text { g } & \text { G } \\ 072 & \text { Z/AHT } & \text { a } & \text { G } \\ 122 & \text { B13 } & \text { d } & \text { A } \\ 071 & \text { B13 } & \text { d } & \text { A }\end{array}$

G
G
G
G
G
G
G
G
G
G
A
A

$\begin{array}{ll}-+-- & +--- \\ -+-- & +-+- \\ -+-- & +-+- \\ -+-- & +-+- \\ -+-- & +-+- \\ -+-- & +-+- \\ -+-- & +-+- \\ -+-- & +-+- \\ -+-- & +-+- \\ -+-- & +-+- \\ -+-- & +-+- \\ ---- & +-+- \\ ---- & +-+-\end{array}$

+----++
++---++
++---++
++--+++
++---++
++-++++
++-++++
++--+++
++--+++
++--+++
++--+++
+---+++
$+--t++$

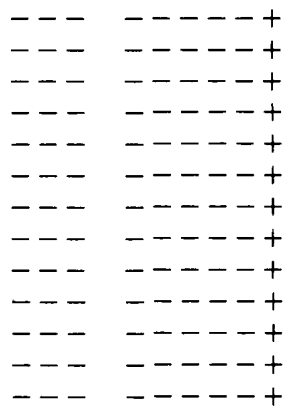

5040510

5040710

5040710

5040710

5040710

5040770

5040770

5040730

5040730

5040730

5040730

1040530

1040530

Group IB (S. mutans)

\begin{tabular}{ll}
147 & OMZ/51 \\
116 & Z/BHT \\
157 & OMZ/71 \\
156 & FA1 \\
077 & FA1 \\
153 & TH21 \\
144 & OMZ/70 \\
143 & OMZ/61 \\
109 & OMZ/61 \\
154 & INGBRITT \\
140 & KHAN \\
121 & 161 \\
184 & BC: 1817 \\
090 & BC: 1817 \\
158 & SE11 \\
155 & FW293 \\
154 & INGBRITT \\
150 & NCTC 10923 \\
067 & LM7=10923 \\
148 & NCTC 10449 \\
008 & NCTC 10449 \\
141 & MCGREGOR \\
134 & E49 \\
132 & 3720 \\
127 & 3720 \\
131 & 151 \\
126 & 4177 \\
089 & BC: 1813 \\
083 & SVIR 544 \\
045 & STREP 206 \\
036 & SVIR 728 \\
026 & R79/1374 \\
017 & R79/2200 \\
009 & ROBERTSON \\
& \\
\hline 19
\end{tabular}

$\begin{array}{lll}\text { G } & ++-- & +-+- \\ \mathrm{G} & ++-- & +-+- \\ \mathrm{G} & ++-- & +-+- \\ \mathrm{G} & ++-- & +-+- \\ \mathrm{G} & ++-- & +-+- \\ \mathrm{G} & ++-- & +-+- \\ \mathrm{G} & -+-- & +-+- \\ \mathrm{G} & -+-- & +-+- \\ \mathrm{G} & -+-- & +-+- \\ \mathrm{G} & -+-- & +-+- \\ \mathrm{G} & -+-- & +-+- \\ \mathrm{G} & -+-- & +-+- \\ \mathrm{G} & -+-- & +-+- \\ \mathrm{G} & -+-- & +-+- \\ \mathrm{G} & -+-- & +-+- \\ \mathrm{G} & -+-- & +-+- \\ \mathrm{G} & -+-- & +-+- \\ \mathrm{G} & -+-- & +-+- \\ \mathrm{G} & -+-- & +-+- \\ \mathrm{G} & -+-- & +-+- \\ \mathrm{G} & -+-- & +-+- \\ \mathrm{G} & -+-- & +-+- \\ \mathrm{G} & -+-- & +-+- \\ \mathrm{G} & -+-- & +-+- \\ \mathrm{G} & -+-- & +-+- \\ \mathrm{G} & -+-- & +-+- \\ \mathrm{G} & -+-- & +-+- \\ \mathrm{G} & -+-- & +-+- \\ \mathrm{G} & -+-- & +-+- \\ \mathrm{G} & -+-- & +-+- \\ \mathrm{G} & -+-- & +-+- \\ \mathrm{G} & -+-- & +-+- \\ \mathrm{G} & -+-- & +-+- \\ \mathrm{G} & -+-- & +-+- \\ & & \\ & -+ & + \\ & -+- & +\end{array}$

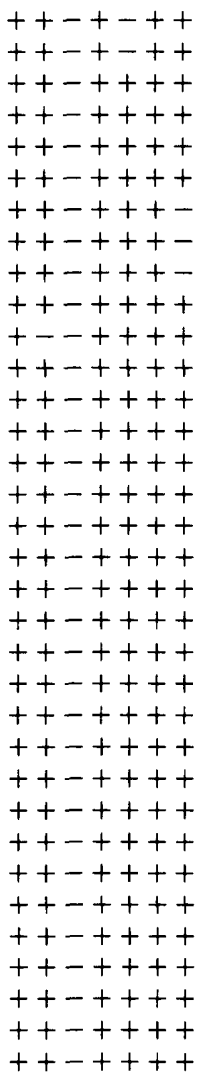

\begin{tabular}{l}
--- \\
--- \\
--- \\
--- \\
--- \\
--- \\
--- \\
--- \\
--- \\
--- \\
--- \\
+-- \\
--- \\
--- \\
--- \\
--- \\
--- \\
--- \\
--- \\
--- \\
--- \\
--- \\
--- \\
--- \\
--- \\
--- \\
--- \\
--- \\
--- \\
--- \\
--- \\
--- \\
\hline
\end{tabular}

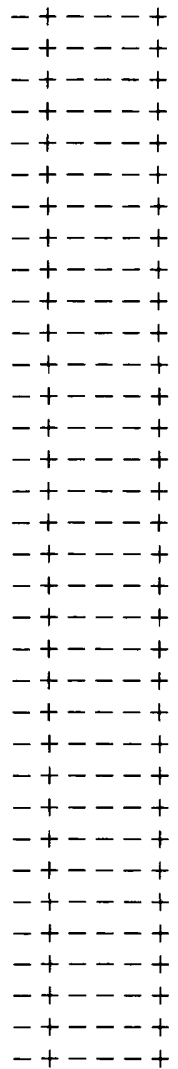

5241750

5241750

5241770

5241770

5241770

5241770

5240760

5240750

5240760

5240770

5240570

5242770

5240770

5240770

5240770

5240770

5240770

5240770

5240770

5240770

5241770

5240770

5240770

5240770

5240770

5240770

5240770

5240770

5240770

5240770

5240770

5240770

5240770

5240770

STH code $=$ code number of strain in the St Thomas's Hospital collection.

Original code $=$ code number supplied by donor.

Ser = serotype.

$\mathrm{H}=$ haemolysis: $\mathrm{A}=$ alpha, $\mathrm{B}=$ beta, $\mathrm{G}=$ gamma (non-haemolytic).

AESU $=$ hydrolysis of arginine, aesculin, starch, urea.

APDL $=$ production of acetoin (VP), $\mathrm{H}_{2} \mathrm{O}_{2}$, dextran, levan

MSARILT = fermentation of mannitol, sorbitol, arabinose, raffinose, inulin, lactose, trehalose.

$\mathrm{Hi}=$ hydrolysis of hippurate.

$\mathrm{RSG}=$ fermentation of ribose, starch, glycogen

PABBPL = enzyme activity for pyrrolidonylarylamidase, $\alpha$-galactosidase, $\beta$-glucuronidase, $\beta$-galactosidase, alkaline phosphatase, leucine aminopeptidase.

Note: The results are in a different order from the arrangement on the API-20STREP gallery, but the API profile number is correct. 
which clusters in group VI with strains resembling $S$. milleri. Group II is reasonably homogeneous, but a small subgroup containing only three strains splits off the main cluster at a dissimilarity distance of about 0.5 units; two of these strains (STH13 and STH174) were identified intuitively as $S$. bovis II, and the third was the atypical mannitol-negative, trehalose-negative reference strain of $S$. bovis I, NCTC 8177.

Group III (30 strains) (table IV), contains all the isolates identified intuitively as $S$. mitior, together with the arginine-positive strains STH139 and the previously unidentified strain STH102. All 30 strains were $\alpha$-haemolytic; all except strains STH139 and STH102 were arginine-negative; and all except strain STH102 produced $\mathrm{H}_{2} \mathrm{O}_{2}$. Group III divides into two subgroups separated by a distance of about 1.8 units. Subgroup IIIA (16 strains) contains only raffinose-positive, $\alpha$-galactosidase-positive and alkaline-phosphatase-positive isolates. It includes all 11 strains previously identified as dextran-positive $S$. mitior (including the reference strain NCTC 7864) and five other strains - the dextran-negative $S$. mitior strains STH21, STH27 and STH58; the unidentified strain STH102 ( $\alpha$-haemolytic, aesculin-positive, argininepositive, $\mathrm{H}_{2} \mathrm{O}_{2}$-negative and dextran-negative); and the dextran-negative, arginine-positive, aesculin-positive strain STH139 which had been identified intuitively as $S$. sanguis. Subgroup IIIB (14 strains) contains all strains intuitively identified as dextran-negative $S$. mitior (including the reference strain NCTC 10712), except for strains STH21, STH27 and STH58 which clustered with subgroup IIIA. The cluster analysis subdivided IIIB into raffinose-positive and raffinose-negative varieties, separated by a distance of about 0.8 units, but this did not appear to be taxonomically significant. It is not possible to create a dichotomous key to allocate $S$. mitior strains uniquely to subgroup IIIA or IIIB. Strains within IIIB tend to be less reactive than those in IIIA, but no reactions are mutually exclusive.

Group IV (36 strains) (table V), contains all organisms intuitively identified as $S$. sanguis with the exception of the atypical reference strain NCTC 7868 which clusters with group VI (S. milleri), and the dextran-negative strain STH139 which clusters with strains resembling $S$. mitior. All members of group IV produced $\mathrm{H}_{2} \mathrm{O}_{2}$ and all except strain STH135 hydrolysed arginine. Two subgroups, IVA (19 strains) and IVB (17 strains), were separated by a distance of about 1.8 units; they may be distinguished by the fermentation of sorbitol-all but one strain of IVA were positive and all of IVB were negative. Both subgroups contained dextrannegative and dextran-positive varieties, but this characteristic does not appear to be taxonomically significant.

Group V (17 strains) (table VI) is homogenous and contains all the $S$. salivarius isolates except the atypical strain STH130 (LINH 33142) which clusters with $S$. milleri strains in group VI. Urease production has been proposed as a diagnostic characteristic for $S$. salivarius. In this study no other species produced this enzyme, but only 14 out of 18 $S$. salivarius strains (including strain STH130) gave positive results.

Group VI (31 strains) (table VI) comprises organisms resembling $S$. milleri and six other strains: two atypical $S$. sanguis reference strains, NCTC 7868 and STH113 (HF/F90A) (equivalent to ATCC 12369), both $\beta$-haemolytic, argininepositive, aesculin-positive, dextran-positive and $\mathrm{H}_{2} \mathrm{O}_{2}$-negative; strain STH130 (LINH 33142), an atypical urease-negative, raffinose-negative, inulinnegative, lactose-negative, $\beta$-galactosidase-negative strain of $S$. salivarius; strain STH28, an atypical arginine-negative and alkaline phosphatase-negative strain identified as $S$. bovis by API-20STREP; and two $\mathrm{H}_{2} \mathrm{O}_{2}$-negative strains, STH11 and STH20, of uncertain identity. Only 10 strains in Group VI reacted with Lancefield's antisera; seven were group $\mathrm{F}$, two group $\mathrm{C}$ and one group $\mathrm{G}$. Haemolysis on blood agar was variable and did not appear to contribute to any natural divisions within this group.

\section{Discussion}

Our results with this collection of viridans streptococci demonstrated that most of the organisms could be classified intuitively by the results of the tests in the API-20STREP kit into the six species defined by Colman and Williams (1972), but there were insufficient strains resembling $S$. bovis II for comment to be made on this subgroup. The most difficult isolates to speciate are organisms resembling $S$. sanguis/S. mitior. We have shown previously that, for this group, a positive result in the API test for the possession of arginine dihydrolase (a test for arginine hydrolysis) correlates well with a high cell-wall rhamnose content, and is characteristic of $S$. sanguis (Price et al., 1986). In contrast, $S$. mitior is API arginine-negative and has a low rhamnose content. Strains of both $S$. sanguis and $S$. mitior can hydrolyse aesculin. With this convention, organisms resembling $S$. sanguis and $S$. mitior can be easily classified. They are also characterised by the production of $\mathrm{H}_{2} \mathrm{O}_{2}$ during 
Table IV. Biochemical and enzymatic reactions of strains in clusters II and III from conventional and API-20STREP tests

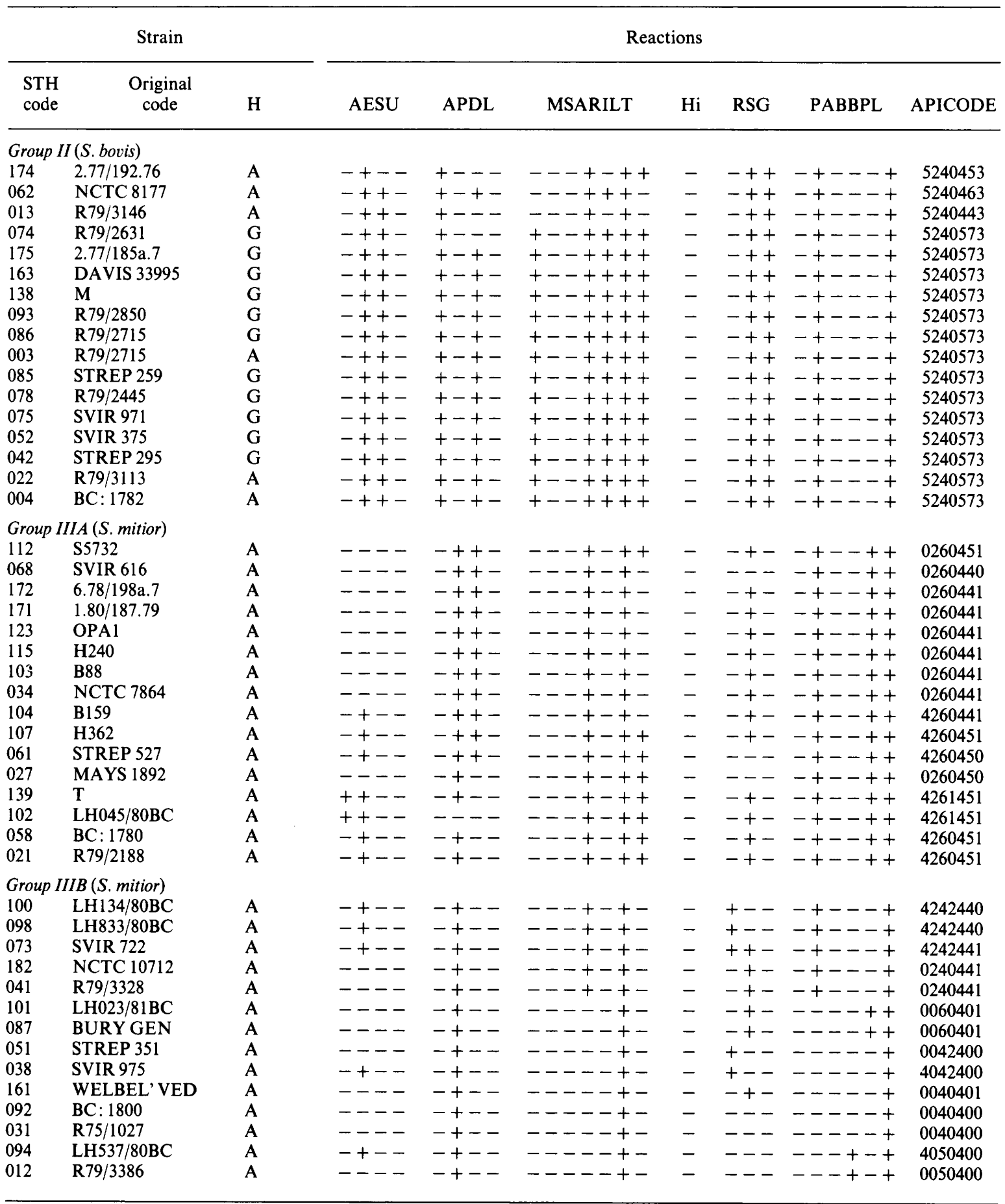

See footnote to table III. 
Table V. Biochemical and enzymatic reactions of strains in cluster IV from conventional and API-20STREP tests

\begin{tabular}{|c|c|c|c|c|c|c|c|c|c|}
\hline \multicolumn{3}{|c|}{ Strain } & \multicolumn{7}{|c|}{ Reactions } \\
\hline $\begin{array}{l}\text { STH } \\
\text { code }\end{array}$ & $\begin{array}{l}\text { Original } \\
\text { code }\end{array}$ & $\mathrm{H}$ & AESU & APDL & MSARILT & $\mathrm{Hi}$ & RSG & PABBPL & APICODE \\
\hline \multicolumn{10}{|c|}{ Group IVA (S. sanguis) } \\
\hline 167 & M371 & A & ++-- & -+-- & ---+-+ & - & --- & -+---+ & 4241050 \\
\hline 160 & WELLB' VED 1 & A & ++-- & -++- & ---+-++ & - & ++- & -+--++ & 4263451 \\
\hline 169 & M408 & A & ++-- & -++- & ---+-++ & - & -+- & -+---+ & 4241451 \\
\hline 137 & $\mathrm{~L}$ & A & ++-- & -++- & ---+-++ & - & -+- & -+---+ & 4241451 \\
\hline 120 & A43 & A & +++- & -++- & ---+++ & - & -+- & -+---+ & 4241471 \\
\hline 106 & $\mathrm{OMZ} / 9$ & $\mathrm{G}$ & +++- & -++- & ---+++ & - & -+- & -+---+ & 4241471 \\
\hline 110 & M19 & A & +--- & -++- & -+-++++ & - & -+- & -+---+ & 0241671 \\
\hline 097 & $\mathrm{LH} 867 / 80 \mathrm{BC}$ & A & ++-- & -++- & ---++-+ & - & -+- & -+--+ & 4241071 \\
\hline 168 & P695 & A & ++-- & -++- & ---+++ & - & -+- & -+---+ & 4241471 \\
\hline 136 & $\mathrm{~K}$ & A & ++-- & -++- & ---++++ & - & -+- & -+---+ & 4241471 \\
\hline 056 & M517 & A & ++-- & -++- & ---+++ & - & -+- & -+---+ & 4241471 \\
\hline 166 & KENDALL & $\mathrm{G}$ & ++-- & -+-- & -----+- & - & -+- & -----+ & 4041401 \\
\hline 177 & NCTC 7863 & A & ++-- & -++- & ----++ & - & -+- & -----+ & 4041411 \\
\hline 162 & BRENCHLEY & A & +++- & -++- & ----++ & - & -+- & ----+ & 4041411 \\
\hline 091 & $\mathrm{BC}: 1821$ & A & +++- & -++- & ----++ & - & -+- & ----+ & 4041430 \\
\hline 088 & $\mathrm{BC}: 1805$ & A & +--- & -+-- & ----++ & - & -+- & ----+ & 0041411 \\
\hline 054 & $\mathrm{~T} 427$ & A & +--- & -+-- & ----+++ & - & -+- & ----+ & 0041431 \\
\hline 173 & $6.77 / 74 a .77$ & A & +--- & -++- & ---+++ & - & -+- & ----+ & 0041431 \\
\hline 015 & STH23 & A & +--- & -++- & ----+++ & - & -+- & -----+ & 0041431 \\
\hline \multicolumn{10}{|c|}{ Group IVB (S. sanguis) } \\
\hline 055 & BC: 1736 & A & ++-- & -+-- & ----++ & - & --- & ----+ & 4061430 \\
\hline 180 & NCTC 10231 & A & ++-- & -++- & ----++ & - & --- & ---++ & 4061430 \\
\hline 128 & H44 & A & ++-- & -++- & ---+++ & - & --- & ----++ & 4061430 \\
\hline 066 & $\mathrm{R} 79 / 3247$ & A & ++-- & -++- & ----++ & - & --- & ----++ & 4061430 \\
\hline 037 & BC: 1746 & $\mathrm{~A}$ & ++-- & -++- & ---+++ & - & --- & ---++ & 4061430 \\
\hline 018 & $\mathrm{BC}: 1770$ & A & ++-- & -++- & ---+++ & - & --- & ---++ & 4061430 \\
\hline 016 & L/SANG & A & ++-- & -++- & ----++ & - & --- & ----++ & 4061430 \\
\hline 135 & J & A & -+-- & -++- & ----++ & - & --- & -----+ & 4040410 \\
\hline 170 & NP506 & A & ++-- & -++- & -----++ & - & --- & -----+ & 4041410 \\
\hline 096 & LH $524 / 80 B C$ & A & ++-- & -+-- & ----++ & - & --- & ----+ & 4041410 \\
\hline 178 & NCTC 7865 & $\mathrm{~A}$ & ++-- & -++- & ----++ & - & --- & ----++ & 4061410 \\
\hline 044 & NCTC 7865 & A & ++-- & -++- & ----++ & - & --- & ---++ & 4061410 \\
\hline 164 & SINGH & A & ++-- & -++- & -----++ & - & --- & ----++ & 4061410 \\
\hline 099 & GPF1 & $\mathrm{A}$ & ++-- & -++- & ----++ & - & --- & ----+ & 4061410 \\
\hline 046 & CARLSSON 903 & A & ++-- & -++- & -----++ & - & --- & $---t+$ & 4061410 \\
\hline 024 & H730 & A & ++-- & -++- & ----++ & - & --- & ----++ & 4061410 \\
\hline 007 & $\mathrm{R} 79 / 3344$ & A & ++-- & -++- & -----++ & - & --- & ----++ & 4061410 \\
\hline
\end{tabular}

See footnote to table III.

growth, but this test is not part of the API20STREP system. Dextran-positive and dextrannegative varieties of both these species were identified by a sensitive test for polysaccharide production.

It has been suggested that the possession of urease (not tested by the API-20STREP kit) is a characteristic of $S$. salivarius (Feltham, 1979); 14 of the 18 strains of $S$. salivarius tested hydrolysed urea, but the reference strains NCTC 8606 and LINH 33142 were urease negative. Organisms of other species gave uniformly negative results in this test.
Thus urea hydrolysis is a useful additional test for the identification of $S$. salivarius, especially if the production of levan is not tested, but it is not definitive.

The S. mutans biotypes of Perch et al. (1974) were closely related but not identical to serotype. Biotype 3 was not well-defined, and on these API20STREP results it would be more useful to characterise it as arginine-positive, raffinose-negative and $\alpha$-galactosidase-negative. In this study, arginine-positive strains of $S$. mutans were usually serotype $b$, and raffinose-negative, $\alpha$-galactosidase- 
Table VI. Biochemical and enzymatic reactions of strains in clusters V and VI from conventional and API-20STREP tests

\begin{tabular}{|c|c|c|c|c|c|c|c|c|c|c|}
\hline \multicolumn{4}{|c|}{ Strain } & \multicolumn{7}{|c|}{ Reactions } \\
\hline $\begin{array}{l}\text { STH } \\
\text { code }\end{array}$ & $\begin{array}{l}\text { Original } \\
\text { code }\end{array}$ & Group* & $\mathbf{H}$ & AESU & APDL & MSARILT & $\mathrm{Hi}$ & RSG & PABBPL & APICODE \\
\hline \multicolumn{11}{|c|}{ Group $V(S$. salivarius $)$} \\
\hline 063 & STREP 136 & & $\mathrm{G}$ & -+-- & +--+ & ---+++ & - & -+- & ---+-+ & 5050461 \\
\hline 053 & R79/2894 & & A & -+-- & +--+ & ---+-+- & - & -+- & ---+-+ & 5050441 \\
\hline 165 & BC: 1967 & & $\mathrm{G}$ & -+-+ & +--+ & ---+-+ & - & -+- & ---+-+ & 5050451 \\
\hline 111 & $6.77 / 16.77$ & & $\mathrm{G}$ & -+-+ & +--+ & ---+-+- & - & -+- & ---+-+ & 5050441 \\
\hline 048 & B 128 & & $\mathrm{G}$ & -+-+ & +--+ & ---+-+- & - & -+- & ---+-+ & 5050441 \\
\hline 057 & STREP 347 & & $\mathbf{A}$ & -+-+ & +--+ & ---+++ & - & -+- & ---+-+ & 5050471 \\
\hline 105 & H167 & & $\mathrm{G}$ & -+-+ & +--+ & ---+++ & - & -+- & ---+-+ & 5050471 \\
\hline 047 & R79/3114 & & $\mathrm{G}$ & -+-+ & +--+ & ---+++ & - & -+- & ---+-+ & 5050470 \\
\hline 181 & NCTC 8606 & & $\mathrm{G}$ & -+-- & +--+ & ---+-++ & - & --- & -+-+++ & 5270450 \\
\hline 043 & $55 x l c$ & & $G$ & -+-+ & +--+ & ---+++ & - & --- & ---+-+ & 5050470 \\
\hline 023 & M36 & & $\mathrm{G}$ & -+-+ & +--+ & ---+++ & - & --- & ---+-+ & 5050470 \\
\hline 014 & $66 \mathrm{xlb}$ & & $\mathrm{G}$ & -+-+ & +--+ & ---+++ & - & --- & ---+-+ & 5050470 \\
\hline 108 & B242 & & $\mathrm{G}$ & -+-+ & +--+ & ---+-++ & - & --- & ---+-+ & 5050450 \\
\hline 050 & STREP 290 & & $\mathrm{G}$ & -+-+ & +--+ & ---+-++ & - & --- & ---+-+ & 5050450 \\
\hline 006 & R79/3385 & & $\mathrm{G}$ & -+-- & +--+ & ---+-++ & - & --- & ---+-+ & 5050450 \\
\hline 183 & QC552 & & B & -+-+ & +--+ & ---+-+- & - & -+- & -+-+++ & 5270445 \\
\hline 005 & QC552 & & B & -+-+ & +--+ & ---+-+- & - & -+- & -+-+++ & 5270445 \\
\hline \multicolumn{11}{|c|}{ Group VI (S. milleri) } \\
\hline 179 & NCTC 7868 & - & B & ++-- & --+- & ----++ & - & --- & ---++ & 4061434 \\
\hline 113 & $\mathrm{HF} / \mathrm{F} 90 \mathrm{~A}$ & - & B & ++-- & --+- & ---+++ & - & --- & -+--++ & 4261474 \\
\hline 070 & COOK 142 & - & $\mathrm{G}$ & ++-- & +--- & +--+-++ & - & -+- & -+--++ & 5261551 \\
\hline 065 & LASKOWSKI & $\mathbf{F}$ & $\mathrm{G}$ & ++-- & +--- & +--+-++ & - & -+- & -+--++ & 5261551 \\
\hline 010 & SVIR 891 & - & B & ++-- & ++-- & ---+-++ & - & -+- & -+--++ & 5261455 \\
\hline 130 & LINH 33142 & - & $G$ & -+-- & +--+ & -----+ & - & -+- & -----+ & 5040011 \\
\hline 028 & STREP 535 & - & $\mathrm{G}$ & -+-- & +--- & -----++ & - & --- & --++-+ & 5450410 \\
\hline 011 & ANDERSON 95 & - & A & --- & +--- & ------- & - & --- & +----+ & 1140000 \\
\hline 084 & MCELROY & $\mathrm{C}$ & B & +--- & +-- & -----++ & - & -+- & ----+ & 1061415 \\
\hline 059 & R79/307 & - & B & +--- & +--- & ------+ & - & --- & ----++ & 1061014 \\
\hline 030 & SVIR 543 & $\mathrm{~F}$ & B & ++-- & +--- & -----+ & - & --- & ---++ & 5061014 \\
\hline 060 & SVIR 412 & - & $\mathrm{G}$ & ++-- & +--- & ----++ & - & -+- & ----++ & 5061411 \\
\hline 049 & 933 & - & $\mathrm{G}$ & ++-- & +--- & ----++ & - & -+- & ----+ & 5061411 \\
\hline 029 & SVIR 931 & - & $\mathrm{G}$ & ++-- & +--- & ----++ & - & -+- & ----+ & 5061411 \\
\hline 082 & SHAW 898 & - & $\mathrm{G}$ & ++-- & +--- & -----++ & - & --- & ----++ & 5061410 \\
\hline 081 & COX 471 & - & $\mathrm{G}$ & ++-- & +--- & ----++ & - & --- & ----++ & 5061410 \\
\hline 025 & WELLS 6782 & - & $\mathrm{G}$ & ++-- & +--- & -----++ & - & --- & ---++ & 5061410 \\
\hline 080 & HUNT 284 & $\mathrm{~F}$ & A & +--- & +--- & -----++ & - & --- & ----++ & 1061410 \\
\hline 129 & G5: 3 & $\mathrm{~F}$ & A & ++-- & +--- & ----++ & - & --- & ---++ & 5061410 \\
\hline 124 & G6: $1 \mathrm{~A}$ & - & A & ++-- & +-- & -----++ & - & --- & ----++ & 5061410 \\
\hline 119 & $\mathrm{G} 4: 2 \mathrm{~A}$ & $\mathrm{~F}$ & A & ++-- & +--- & -----+ & - & --- & ----++ & 5061410 \\
\hline 114 & G3: 1 & $\mathrm{C}$ & A & ++-- & +--- & ----++ & - & --- & ----+ & 5061410 \\
\hline 069 & STREP 566 & - & A & ++-- & +--- & -----++ & - & --- & ----++ & 5061410 \\
\hline 176 & $2.81 / 269$ & $\mathrm{G}$ & A & ++-- & ++-- & -----++ & - & -+- & ----++ & 5061411 \\
\hline 064 & WALSH 1974 & $\mathrm{~F}$ & A & ++-- & +--- & -----++ & - & -+- & ---++ & 5061411 \\
\hline 040 & R79/3327 & - & A & ++-- & ++-- & -----++ & - & --- & ----++ & 5061410 \\
\hline 039 & R79/3340 & - & A & ++-- & ++-- & ----++ & - & --- & ---++ & 5061410 \\
\hline 020 & 850356 & & A & +--- & ---- & -----+ & - & --- & ---++ & 0061010 \\
\hline 019 & STREP 536 & $\mathrm{~F}$ & A & ++-- & +--- & -----+ & - & -++ & ----+ & 5061013 \\
\hline 079 & STREP 562 & - & A & ++-- & +--- & -----+ & - & --- & ----++ & 5061010 \\
\hline 002 & STREP 411 & - & A & ++-- & +--- & ------+ & - & --- & ---++ & 5061010 \\
\hline
\end{tabular}

See footnote to table III.

*Lancefield group. 
negative strains were usually serotypes $\mathrm{d}$ or $\mathrm{g}$. These results support the views of Hardie and others (Hardie and Bowden, 1976; Hardie and Marsh, 1978; Hamada and Slade, 1980) that the various serotypes of $S$. mutans are not well defined and are inconsistently related to biotype.

Our API-20STREP results show that many of the reference strains of viridans streptococci are atypical in their reactions -in particular strains B13 (S. mutans), NCTC 8177 (S. bovis), NCTC 8606 and LINH 33142 (S. salivarius), NCTC 7868 and ATCC 12369 (S. sanguis).

Different methods of cluster analysis produced different taxonomic results. Ward's method combined with the Squared Euclidian Distance metric produced a satisfactory cluster result that corresponded closely with the intuitive classification. The same six species were clearly separated, each about 5 units from its nearest neighbour. There were no major subdivisions of $S$. salivarius, $S$. milleri or $S$. bovis, but subgroups of $S$. mutans, $S$. sanguis and $S$. mitior were distinguished, each pair separated by about 2 units. Additional smaller subclusters separated from larger groups by less than one unit did not appear to be significant. The subdivision of $S$. mutans did not correspond to the Perch biotypes or to serotype. $S$. mutans strains of subgroup IA could be distinguished from IB only by the possession of $\alpha$-galactosidase, and this division does not seem very useful.

$S$. sanguis and $S$. mitior strains clustered separately, closely approximating to the intuitive classification. The cluster analysis divided $S$. sanguis by ribose fermentation, but table $\mathrm{V}$ suggests that the group might equally well be separated by inulin or raffinose fermentation, or by the possession of $\alpha$ galactosidase or alkaline phosphatase. Thus the subdivision of $S$. sanguis did not seem to be useful. The cluster subdivision of $S$. mitior was not based on mutually exclusive reactions, and was also unhelpful. The production of dextran did not contribute to any significant division of either $S$.

\section{REFERENCES}

Appelbaum P C et al. 1984 Comparative evaluation of the API $20 \mathrm{~S}$ system and the AutoMicrobic System Gram-positive identification card for species identification of streptococci. Journal of Clinical Microbiology 19: 164-168.

Bailey R W, Oxford A E 1958 Pre-requisite for dextran production by Streptococcus bovis. Nature 182: 185-186.

Bailey R W, Oxford A E 1959 The nature of the polysaccharides of the dextran-producing organisms Leuconostoc mesenteroides, L. dextranicum and Streptococci bovis. Journal of General Microbiology 20 : 258-266.

Colman G, Williams R E O 1972 Taxonomy of some human sanguis or $S$. mitior, and this analysis did not support the existence of a raffinose-positive $S$. mitis group (Facklam, 1977).

These results suggest that $\alpha$-haemolytic $\mathrm{H}_{2} \mathrm{O}_{2}$ positive, acetoin-negative viridans streptococci should be classified into $S$. sanguis and $S$. mitior on the basis of arginine hydrolysis, and that further subdivisions are as yet unjustified. Further evidence for this scheme is provided by the DNA studies of Coykendall and his colleagues which also support the taxa $S$. sanguis and $S$. mitior, but not $S$. mitis or speciation by dextran production (Coykendall and Specht, 1975; Coykendall and Munzenmaier, 1978).

There is a need for international agreement on the taxonomy and nomenclature of viridans streptococci. The present study supports the Colman and Williams classification of $S$. mutans, $S$. bovis, $S$. salivarius, $S$. milleri, $S$. sanguis and $S$. mitior, except that dextran production does not appear to be a taxonomically significant character. With this scheme, the viridans streptococci can be speciated or identified fairly easily with the API-20STREP system if small subgroups are ignored and if $S$. sanguis and $S$. mitior are distinguished by arginine hydrolysis. The tests in the API-20STREP system may be more reliable than conventional test methods, and are probably reproducible. Additional tests for the production of $\mathrm{H}_{2} \mathrm{O}_{2}$ and the hydrolysis of urea are useful but tests for polysaccharide production are not. The API-20STREP identification codes do not correspond to the simple classification described here, and it would be useful for these to be revised.

We are indebted to the following colleagues for gifts of viridans streptococci: Dr D. Beighton, Royal College of Surgeons, Dental Research Unit; Dr J. M. Hardie, Department of Oral Microbiology, The London Hospital Medical College; Professor J. D. Williams, Department of Microbiology, The London Hospital Medical College; Dr M. S. Shafi, Department of Microbiology, Central Middlesex Hospital; Dr G. Colman and Ms L. Ball, Division of Hospital Infection, Central Public Health Laboratory, Colindale, London.

viridans streptococci. In: Wannamaker L W, Matsen J M (eds) Streptococci and streptococcal diseases. Academic Press, New York, pp 281-299.

Colman G 1976 The viridans streptococci. In: de Louvois J (ed) Selected topics in clinical bacteriology. Bailliere Tindal, London, pp 179-198.

Colman G, Ball L C 1984 Identification of streptococci in a medical laboratory. Journal of Applied Bacteriology 57: 114.

Cowan S T 1974 Cowan and Steel's Manual for the identification of medical bacteria, 2nd edn. Cambridge University Press, Cambridge.

Coykendall A L, Specht P A 1975 DNA base sequence 
homologies among strains of Streptococcus sanguis. Journal of General Microbiology 91 : 92-98.

Coykendall A L, Munzenmaier A J 1978 Deoxyribonucleic acid base sequence studies on glucan-producing and glucannegative strains of Streptococcus mitior. International Journal of Systematic Bacteriology 28: 511-515.

Coykendall A L, Wesbecher P M, Gustafson K B 1987 "Streptococcus milleri", Streptococcus constellatus and Streptococcus intermedius are later synonyms of Streptococcus anginosus. International Journal of Systematic Bacteriology 37: 222-228.

Drucker D B, Melville T H 1971 The classification of some oral streptococci of human or rat origin. Archives of Oral Biology 16: 845-853.

Facklam R R 1972 Recognition of group D streptococcal species of human origin by biochemical and physiological tests. Applied Microbiology 23: 1131-1139.

Facklam R R 1977 Physiological differentiation of viridans streptococci. Journal of Clinical Microbiology 5: 184-201.

Facklam R R 1984 The major differences in the American and British Streptococcus taxonomy schemes with special reference to Streptococcus milleri. European Journal of Clinical Microbiology 3: 91-93.

Feltham R K A 1979 A taxonomic study of the genus Streptococcus. In: Parker M T (ed) Pathogenic streptococci. Reedbooks, Chertsey, 247-248.

Gower J C 1967 A comparison of some methods of cluster analysis. Biometrics 23: 623-637.

Hamada S, Slade H D 1980 Biology, immunology and cariogenicity of Streptococcus mutans. Microbiological Reviews 44: 331-384.

Hardie J M, Bowden G H 1976 Physiological classification of oral viridans streptococci. Journal of Dental Research 55: A166-A176.

Hardie J M, Marsh P D 1978 Streptococci and the human oral flora. In: Skinner F A, Quesnel L B (eds) Streptococci. Academic Press, London, pp 157-206.

Hardie J M 1986 Oral streptococci. In: Sneath P H A et al. (eds) Bergey's Manual of systematic bacteriology, vol 2, Williams and Wilkins, Baltimore, pp 1054-1063.

Medical Research Council 1929 A system of bacteriology in relation to medicine, vol II. HMSO, London, pp 22-43.

Nachamkin I, Lynch J R, Dalton H P 1982 Evaluation of a rapid system for species identification of alpha-hemolytic streptococci. Journal of Clinical Microbiology 16: 521-524.

Parker M T, Ball L C 1976 Streptococci and aerococci associated with systemic infection in man. Journal of Medical Microbiology 9: 275-302.

Perch B, Kjems E, Ravn T 1974 Biochemical and serological properties of Streptococcus mutans from various human and animal sources. Acta Pathologica et Microbiologica Scandinavica B82: 357-370.

Price T, French G L, Talsania H, Phillips I 1986 Differentiation of Streptococcus sanguis and S. mitior by whole-cell rhamnose content and possession of arginine dihydrolase. Journal of Medical Microbiology 21 : 189-197.

Sherman J M 1937 The streptococci. Bacteriological Reviews 1: 3-97.

Sneath P H A 1957 The application of computers to taxonomy. Journal of General Microbiology 17: 201-226.

Sokal R R, Sneath P H A 1973 Principles of numerical taxonomy. W H Freeman, San Francisco.

Waitkins S A, Ball L C, Fraser C A M 1980 A shortened scheme for the identification of indifferent streptococci. Journal of Clinical Pathology 33 : 47-52.

Ward J H 1963 Hierarchical grouping to optimize an objective function. Journal of the American Statistical Association 58: 236-244.

Wishart D 1975 Clustan I C program and user manual. Computer Centre, University College, London. 